seizure threshold in 100 people with depression. using an Ectron Series 5A, comment that this machine is not underpowered. Our experience contradicts this conclusion.

Recently, we used our Department's Ectron Series $5 \mathrm{~A}$ to treat an 87-year-old bald gentleman with a severe depressive illness characterised by agitation. minimal speech and poor food and fluid intake, who was resisting all interactions. He had a past history of two depressive episodes, the first 40 years ago was treated with electroconvulsive therapy (ECT) and the second in 1986 with dothiepin, which he had been maintained on since. Premorbidly he had been an anxious man with an active social life. There was no evidence of dementia. He had a history of ischaemic heart disease and ventricular tachycardia for which he took amiodarone $100 \mathrm{mg}$. He had an aortic aneurysm repair in 1986. He was prescribed aspirin for arteriosclerosis and thyroxine replacement therapy for hypothyroidism, diagnosed in 1986.

At commencement of ECT he was receiving clomipramine $10 \mathrm{mg}$ three times daily, $1 \mathrm{mg}$ trifluoperazine twice daily and zolpidem $10 \mathrm{mg}$ at night. Over the course of the ECT treatment the medication was altered to clomipramine $25 \mathrm{mg}$ three times daily and trifluoperazine $3 \mathrm{mg}$ twice daily. He also required intravenous fluids to maintain hydration.

ECT was given according to local protocol, using the stimulus dosing technique in line with College recommendations. The Ectron $5 \mathrm{~A}$ machine has a maximum output of 700 millicoulombs $(\mathrm{mC})$. The patient received a total of 21 electrode applications during 12 general anaesthetics. No satisfactory fit occurred until the maximum setting was used on the fourth and fifth general anaesthetics. No fit occurred on the sixth general anaesthetic, presumably due to increasing seizure threshold (Sackheim et al, 1987). Caffeine augmentation (250 $\mathrm{mg} \mathrm{iv}$ ) then produced satisfactory fits on the seventh and eighth general anaesthetics, but no further fits occurred.

Clinically this man remained severely depressed with low nutrient intake. In view of his condition he was transferred to the Manchester Royal Infirmary where a Thymatron DGX machine was available. Satisfactory fits occurred at $750 \mathrm{mC}$ and he is now making progress after seven general anaesthetics.

We therefore disagree with the conclusion that the Ectron Series 5A ECT machine is not significantly underpowered. For most patients it is adequate but for patients with a high seizure threshold, who are often elderly, it is underpowered and can result in crucial delays in the effective administration of this potentially lifesaving treatment.

SACKheim. H. A., Decina. P.. Prohovnik. I., et al (1987)

Seizure threshold in electroconvulsive therapy - effects of sex, age, electrode placement and number of treatments. Archives of General Psychiatry. 44, 355360.

Jean Galloway, Consultant Psychiatrist, ANDREW BLAKEY, Consultant Psychiatrist, East Cheshire NHS Trust, Macclesfield District General Hospital, Victoria Road, Macclesfield, Cheshire SK10 3BL: and SUSAN BENBOW, Consultant Psychiatrist, Carisbrooke Resource Centre, Wenlock Way, Gorton, Manchester M12 5LF

\section{Legal and contractual implications of the informal admission of psychiatric patients: a rejoinder}

Sir: Dr Azuonye (Psychiatric Bulletin, August 1998, 22, 501-505) states that "informal admission is the reception into hospital of a patient who either positively consents to admission or does not positively resist being taken into hospital". He is in fact describing two groups of patients, the former being voluntary patients, and the latter being informal patients. I would draw his attention to the comments of Lord Goff of Chieveley on 25 June 1998 in presenting the judgment of the House of Lords in the case of In Re: $L$ (by his next friend G.E.), who stated: "Both are admitted under section 131(1) without the formalities and procedures for admission necessary for detention under the Act. Strictly speaking, therefore, both groups could be described as informal patients but it is convenient to confine that description to those who are not voluntary patients".

Dr Azuonye points out that by virtue of accepting admission (presumably referring to voluntary patients) the patients agree to bide by the rules of the ward. He also implies that a voluntary admission places upon them an obligation of "refraining from unprovoked attacks on other patients and staff, not destroying hospital property". I would suggest that these are obligations that are incumbent upon all of us under common law, and not merely upon patients as a result of their voluntary admission to hospital.

Finally, Dr Azuonye states, again in accordance with good practice, "nursing and/or medical staff should be able to feel satisfied that any patient ... can safely go out of the hospital before allowing him or her to do so ..." and he goes on to quote the recent case of a young man who committed an armed robbery while out on a walk from his rehabilitation ward. I would suggest that the overriding issues that exercise the minds of health care professionals in making the sort of assessments that Dr Azuonye suggests are the risk of harm that the patient poses to himself and to others. Incidents such as the 
commission of armed robberies do not usually figure highly in the considerations of nursing and medical staff, and, in any case, are almost impossible to predict with any certainty.

AKInTUNDE AKInKunMI, Consultant Forensic Psychiatrist, Camlet Lodge Regional Secure Unit, Chase Farm Hospital, Enfield EN2 8JL

\section{R. D. Laing revisited}

Sir: The article on R. D. Laing (Psychiatric Bulletin, July 1998, 22, 452-456) was most interesting. Dr Beveridge states that "his last words were that he did not want a doctor to be called". Perhaps the author, speaking in Edinburgh. wished to spare the susceptibilities of the Scottish Division, or those of the Psychiatric Bulletin readers. Laing's last words could certainly be regarded as anti-medical. They were "Doctor, what fucking doctor." (Laing, 1994).
LAING, A. D. (1994) R. D. Laing: A Biography. London: Peter Owen.

D. Peter Birkett, 2 Copeland Drive, Suffern, New York 10901: e-mail: dpb1@columbia.edu

\section{'Military Munchausen's': assessment of factitious claims of military service in psychiatric patients}

Sir: If Martin Baggaley (Psychiatric Bulletin. March 1998, 22, 153-154) (officers have five figure service numbers, other ranks eight) and Ian Palmer (Psychiatric Bulletin. August 1998, 22. 521) (officers have six figure service numbers, other ranks eight) are to be believed then I can only assume that my military service was factitious - Roger Bloor, Sqn Ldr RAF (retired), service number 5201639 .

ROGER BLOOR, Consultant and Senior Clinical Lecturer, University of Keele, EMU, City General Hospital, Newcastle Road. Stoke on Trent. Staffordshire ST4 6QG

\section{Council Report CR53 Assessment and Clinical Management of Risk of Harm to Other People}

The assessment and clinical management of the risk of a psychiatric patient causing harm to another person is an integral part of psychiatric practice. These guidance notes are intended to assist clinicians by providing an aide memoire to good clinical practice. Although intended specifically for psychiatrists, this guidance may be useful to other health professionals as all members of the multidisciplinary team have a role to play in risk assessment and risk management.

CR53, £3.00, April 1996

Available from Book Sales, Royal College of Psychiatrists 17 Belgrave Square, London SWIX 8PG

$\mathrm{Tel}+44$ (0) 1712352351 (extension 146), Fax +44 (0) 1712451231

The latest information on College publications is available on the Internet at www.rcpsych.oc.uk 